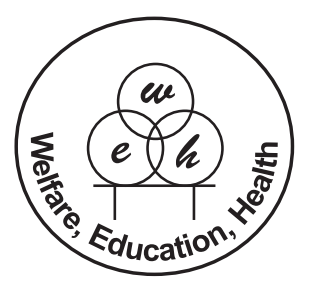

Journal of PharmaSciTech

ISSN: 22313788 (Print)

23214376 (Online)

\title{
Utilization of Acid Dyes for Spectrophotometric Determination of Moxifloxacin and Enrofloxacin Hydrochlorides in Dosage Forms
}

\author{
A.S. Amin, H.A.M. Hendawy, E.M. Mabrouk, N.I. Khamis
}

Department of Chemistry, Faculty of Science, Benha University, Benha-13511, Egypt

*Correspondence: asamin2005@hotmail.com (Tel.: 00201205225223)

\author{
Article Info: \\ Received: 28.03.2019 \\ Accepted: 20.05 .2019 \\ Available online: 01.9 .2020 \\ https://doi.org/10.33981/JPST.2020.v09i01.003
}

\section{Abstract}

Simple, rapid and extractive spectrophotometric methods were developed for the determination of some fluoroquinolone antibiotics: moxifloxacin hydrochloride (MXF), and enrofloxacin (ENF) in pure forms and pharmaceutical formulations. These methods are based on the formation of ion-pair complexes between the basic drugs and acid dyes, namely, methylene blue (MB) and methyl orange (MO) in acidic buffer solutions. The formed complexes were extracted with chloroform and measured at 416, and $422 \mathrm{~nm}$ for MB and M0 respectively, for MXF; at 415 and $420 \mathrm{~nm}$ for MB and MO respectively, for ENF. The analytical parameters and their effects are investigated. Beer's law was obeyed in the ranges 2.0-20, 4.0-24, and 3.0-30 and 3.0-18 $\mu \mathrm{g} / \mathrm{ml}$ for the drug MXF and ENF using MB and M0, respectively. The proposed methods have been applied successfully for the analysis of the studied drugs in pure forms and pharmaceutical formulations. Statistical comparison of the results with the reference methods showed excellent agreement and indicated no significant difference in accuracy and precision.

Keywords: Pharmaceutical analysis, acidic dyes, fluoroquinolones antibiotics, dosage forms.

\section{Introduction}

Fluoroquinolones are the second-generation members of quinolone antibiotics fluorinated in position 6 and bearing a piperazinyl moiety at position. They are considered to be the most effective Gram-positive and Gram-negative pathogens to combat infection caused by microorganisms that are resistant to other microbials, such as tetracyclines. Also, they have some activity against mycobacteria, mycoplasmas, rickettsias, and the protozoan Plasmodium falciparum [1-3]. There is a substantial body of literature related to both the mechanism of their action as DNA gyrase inhibitors and the influence of systematic structural modifications on their biological activity. Moxifloxacin (MXF) is $\{1$-cyclopropyl-7-[2,8-diazobicyclo (4.3.0) nonane]-6-fluoro-8-methoxy-1,4 dihydro-4-oxo-3-quinolone carboxylic acid\}. Enrofloxacin (ENF) is (1-cyclopropyl-7-(4-ethyl-1piperazinyl)-6-fluoro-1,4-dihydro-4-oxo-3-quinolone carboxylic acid) (Figure 1). MXF is fourth-generation synthetic broad-spectrum 8methoxy fluoroquinolone antibacterial drug derivatives. Due to their clinical advantages, MXF is receiving a great interest and there was an increase in number of their pharmaceutical dosage forms in the market in the recent past. Enrofloxacin is the first fluoroquinolone developed for veterinary application and is potentially available for the treatment of some urinary tract, respiratory tract, and skin infectious diseases in pets and livestock [2]. There are no official (pharmacopoeia) methods that have been found for the assay of MXF in their pharmaceutical formulations. ENF is official in the United States Pharmacopeia (USP) [4].<smiles>COc1c(N2C[C@H]3NCCC[C@@H]3C2)c(F)cc2c(=O)c(C(=O)O)cn(C3CC3)c12</smiles>

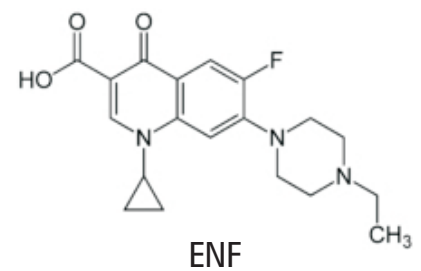

Figure 1: The chemical structure of the studied fluoroquinolones
Several methods have been reported for the determination of fluoroquinolones either in pure forms, dosage forms, or biological fluids like chromatography [5-9], microchip electrophoresis [10], chiral counter-current chromatography [11], capillary zone electrophoresis [12], electrochemistry [13-15], atomic absorption spectrometry [16, 17], and spectrofluorimetry [18-20] and potentiometry [21]. However, these methods are expensive and not available at most quality control laboratories. For routine analysis of the studied drugs, a simple, rapid, and cost effective analytical method was required.

The spectrophotometric technique continues to be the most preferred method for the assay of different classes of drugs in pure, pharmaceutical formulations and in biological samples, for its simplicity and reasonable sensitivity with significant economical advantages. Spectrophotometric methods are reported for the assay of MXF [16, 22-29] and ENF [17, 30-36]. These methods were associated with some major drawbacks such as decreased selectivity due to measurement in ultraviolet region and/or decreased simplicity of the assay procedure (e.g., tedious precipitation, heating, or liquid-liquid extraction steps in the ion pair formation-based methods). For these reasons, it was worthwhile to develop a new simple and selective spectrophotometric method for the determination of the studied drugs in their pharmaceutical dosage forms. In the present work, the development of accurate and precise extractive spectrophotometric methods is reported based on the chloroform soluble ion-pair complexes between the studied fluoroquinolone antibiotics (MXF, and ENF) and some acid dyes (MB, or $\mathrm{MO}$ ). The absorbance measurements were measured at optimum wavelengths. The proposed methods were applied successfully for the determination of the studied drugs in pure and dosage forms. No interference was observed from the additives. The methods provide rapid, economic procedures and more sensitive compared to the previously reported spectrophotometric methods. These methods were validated by the statistical data.

\section{Experimental}

Materials and Methods 


\section{Apparatus}

All absorption spectra were made using JASCO 530V (UV-Visible) spectrophotometer (Japan) with a scanning speed of $200 \mathrm{~nm} / \mathrm{min}$ and a band width of $2.0 \mathrm{~nm}$, equipped with $10 \mathrm{~mm}$ matched quartz cells. The $\mathrm{pH}$ values of different buffer solutions were checked using a Hanna pH-meter instrument (pH 211) (Romania) equipped with a combined glass-calomel electrode.

All reagents and chemicals used were of analytical or pharmaceutical grade and all solutions were prepared fresh daily.

Pharmaceutical grade Moxifloxacin hydrochloride (MXF) reference standard was provided by Sabaa, Kahira Company, Egypt. Enrofloxacin (ENF) was kindly provided by Pharma Swede, Egypt (AVICO).

All pharmaceutical preparations were obtained from commercial sources in the local markets. Avelox tablets were obtained from Bayer, Germany, labeled to contain $400 \mathrm{mg}$ MXF per tablet. Moxiflox tablets were obtained from EVA Pharm. \& Chem. Ind. Company, Egypt, labeled to contain $400 \mathrm{mg}$ MXF per tablet. Moxifloxacin tablets were obtained from Sabaa International Company for Pharmaceuticals and Chemical Industries, S.A.E., labeled to contain $400 \mathrm{mg}$ MXF per tablet. Enrocin $10 \%$ injectable (Alexandria Company for Pharmaceuticals and Chemical Industries, Alexandria, Egypt) was labeled to contain $10 \%$ ENF and Avitryl 20\% injectable (AVICO Veterinary Pharmaceuticals) was labeled to contain $200 \mathrm{mg}$ ENR.

\section{Preparation of stock standard solutions}

Stock standard solutions of MXF, and ENF $\left(100 \mu \mathrm{g} \mathrm{ml}^{-} 1\right.$ and $1.0 \times 10^{-3}$ $\mathrm{M})$ were prepared by dissolving an exact weight of pure drugs in least amount of 0.1 (M) HCl; the mixture was warmed at $50^{\circ} \mathrm{C}$ in a water bath for $5.0 \mathrm{~min}$, agitated by an electrical shaker for another $5.0 \mathrm{~min}$, cooled to room temperature, and diluted to $100 \mathrm{ml}$ with by distilled water in a $100 \mathrm{ml}$ measuring flask. The standard solutions were found stable for at least one week without alteration when kept in an amber colored bottle and stored in a refrigerator when not in use.

\section{Reagents}

Methyene blue (MB), and methyl orange (MO) (BDH Chemicals Ltd., Poole, England) were used without further purification. Stock solutions $\left(1.0 \times 10^{-3} \mathrm{M}\right)$ of reagents were prepared by dissolving the appropriate weight of each reagent in $10 \mathrm{ml}$ of $96 \%$ ethanol and diluted to $100 \mathrm{ml}$ with bi-distilled water. These solutions are stable for at least one week if kept in the refrigerator.

Series of buffer solutions of $\mathrm{KCl}-\mathrm{HCl}(\mathrm{pH}=1.5-4.2), \mathrm{NaOAc}-\mathrm{HCl}(\mathrm{Ac}=$ acetyl) $(\mathrm{pH}=1.99-4.92), \mathrm{NaOAc}-\mathrm{AcOH}(\mathrm{pH}=3.0-5.6)$, and potassium hydrogen phthalate- $\mathrm{HCl}(\mathrm{pH}=2.0-7.0)$ were prepared by following the standard methods [37].

\section{General procedures \\ For MXF}

Aliquots of $(0.1-3.0 \mathrm{ml})$ the standard drug solution $\left(100 \mu \mathrm{g} \mathrm{ml}^{-1}\right)$ were transferred to $10 \mathrm{ml}$ measuring flasks and added $2.0 \mathrm{ml}$ of acetate buffers of $\mathrm{pH} 3.0$ and 3.5 using $\mathrm{MB}$ and $\mathrm{MO}$, respectively and then added $2.0 \mathrm{ml}$ of all reagent solutions $\left(1.0 \times 10^{-3} \mathrm{M}\right)$. The mixture was extracted twice with $5.0 \mathrm{ml}$ chloroform by shaking for $2.0 \mathrm{~min}$ and then allowed to stand for clear separation of the two phases and the chloroform layer was passed through anhydrous sodium sulphate. The absorbance of the yellow colored complexes was measured at 416 , and $422 \mathrm{~nm}$, using MB and MO respectively, against corresponding reagent blank similarly prepared. All measurements were made at room temperature $\left(25 \pm 2^{\circ} \mathrm{C}\right)$. The procedures were repeated for other analyzes aliquots and calibration plots were drawn to calculate the amount of drugs in unknown analyze samples.

\section{For ENF}

Aliquots of $(0.2-2.4 \mathrm{ml})$ the standard drug solution $\left(100 \mu \mathrm{g} \mathrm{m}^{-1}\right)$ were transferred to $10 \mathrm{ml}$ measuring flasks and added $2.0 \mathrm{ml}$ of acetate buffer of $\mathrm{pH} 3.0$ using $\mathrm{MB}$ and $\mathrm{MO}$ and then added to $2.0 \mathrm{ml}$ of reagent solutions $\left(1.0 \times 10^{-3} \mathrm{M}\right)$. The mixture was extracted twice with $5.0 \mathrm{ml}$ chloroform by shaking for $2.0 \mathrm{~min}$ and then allowed to stand for clear separation of the two phases and the chloroform layer was passed through anhydrous sodium sulphate. The absorbance of the yellow colored complexes was measured at 415 and $420 \mathrm{~nm}$ using $\mathrm{MB}$ and $\mathrm{MO}$, respectively, against corresponding reagent blank similarly prepared. All measurements were made at room temperature $\left(25 \pm 2^{\circ} \mathrm{C}\right)$. The procedures were repeated for other analyzes aliquots and calibration plots were drawn to calculate the amount of drug in unknown analyze samples.

\section{Applications to pharmaceutical formulations \\ Procedure for tablets}

The contents of ten tablets (Avelox or Moxiflox) labeled to contain $400 \mathrm{mg}$ MXF per tablet were crushed, powdered, and weighted out and the average weight of one tablet was determined. An accurate weight equivalent to $10 \mathrm{mg} \mathrm{MXF}$ was dissolved in $20 \mathrm{ml}$ of $0.5 \mathrm{M} \mathrm{HCl}$ with shaking for $5.0 \mathrm{~min}$ and filtered. The filtrate was diluted to $100 \mathrm{ml}$ with bi-distilled water in a $100 \mathrm{ml}$ measuring flask to give $100 \mu \mathrm{g} \mathrm{ml}^{-1}$ stock solutions. An aliquot of the diluted drug solution was treated as described previously.

\section{Procedure for injection}

Accurate volumes of Enrocin $10 \%$ or Avitryl $20 \%$ of injectable quantity equivalent to $200 \mathrm{mg}$ were extracted with $10 \mathrm{ml}$ of 0.5 (M) HCl, diluted with water, and sonicated for about $5.0 \mathrm{~min}$. The extracts were transferred into $100 \mathrm{ml}$ volumetric flasks and then diluted to volume with by distilled water. Aliquots of these solutions were transferred into a series of $10 \mathrm{ml}$ volumetric flasks, and the analysis was completed as previously mentioned.

\section{Stoichiometric relationship}

The stoichiometric ratios of the ion-associates formed between the drugs under investigation and the reagents were determined by applying the continuous variation [38] and the molar ratio [39] methods at the wavelengths of maximum absorbance. In continuous variation method, equimolar solutions were employed: $5.0 \times 10^{-4} \mathrm{M}$ standard solutions of drug and $5.0 \times 10^{-4} \mathrm{M}$ solutions of dye were used. A series of solutions was prepared in which the total volume of the studied drugs and the dye was kept at $2.0 \mathrm{ml}$. The drug and reagent were mixed in various complementary proportions $(0: 2,0.2$ : $1.8,0.4: 1.6, \ldots, 2: 0$, inclusive) and completed to volume in a $10 \mathrm{ml}$ calibrated flask with the appropriate solvent for extraction following the above mentioned procedure. In the molar ratio method, the concentrations of, MXF, and ENF are kept constant $(1.0 \mathrm{ml}$ of $5.0 \mathrm{x}$ $\left.10^{-4} \mathrm{M}\right)$ while that of dyes $\left(5.0 \times 10^{-4} \mathrm{M}\right)$ are regularly varied $(0.2-2.4$ $\mathrm{ml})$. The absorbance of the prepared solutions optimum is measured at optimum condition at wavelength for each complex.

\section{Results and Discussion}

\section{Absorption spectra}

The nitrogenous drugs are present in positively charged protonated forms and anionic dyes present mainly in anionic form at $\mathrm{pH} \geqslant 2.5$. So when treated with an acid dye at $\mathrm{pH}$ range 2.8-4.0 of acidic buffers solutions, a yellow ion-pair complex which is extracted with chloroform is formed. The absorption spectra of the ion-pair complexes, which were formed between MXF, or ENF and reagents, were measured in the range $350-550 \mathrm{~nm}$ against the blank solution. The ion-pair complexes of MXF and MB, and MO show maximum absorbance at 416, and $422 \mathrm{~nm}$, respectively; and for ENF and MB and MO show maximum absorbance at 415 and $420 \mathrm{~nm}$, respectively. 


\section{Optimum reaction conditions for complex formation}

The optimization of the methods was carefully studied to achieve complete reaction formation, highest sensitivity, and maximum absorbance.

\section{Effects of $\mathrm{pH}$ on ion-pair formation}

The effect of $\mathrm{pH}$ on the drug-reagent complex was studied by extracting the colored complexes in the presence of various buffers. It was noticed that the maximum color intensity and highest absorbance value were observed in $\mathrm{NaOAc}-\mathrm{AcOH}$ buffer of $\mathrm{pH} 3.0$ or 3.5 using $\mathrm{MB}$, for MXF and ERF respectively. For ENF, highest absorbance was observed in $\mathrm{NaOAc}-\mathrm{AcOH}$ buffer of pH 3.0 using $\mathrm{MR}$ or $\mathrm{MO}$, in addition to the stability of the color without affecting the absorbance at the optimum $\mathrm{pH}$ values (Figure 2). Further, $2.0 \mathrm{ml}$ of the buffers solutions gave maximum absorbance and reproducible results.

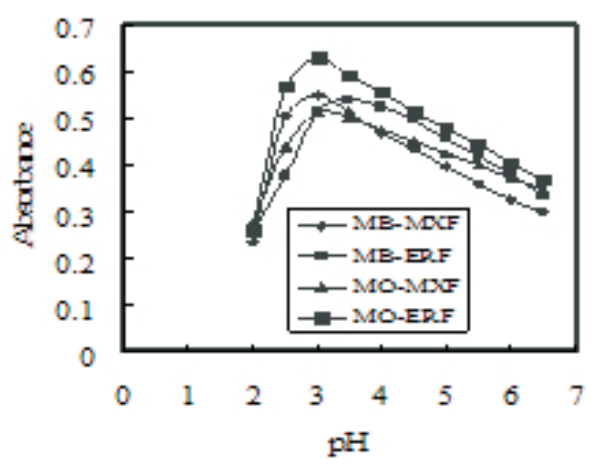

Figure 2: Effect of $\mathrm{pH}$ values on the complexation of $15 \mu \mathrm{g} / \mathrm{ml}$ of studied drugs using $\mathrm{MB}$ and $\mathrm{MO}$

\section{Effect of extracting solvents}

The effect of several organic solvents, namely, carbon tetrachloride, chloroform, methanol, ethanol, acetonitrile, n-butanol, benzene, acetone, ethyl acetate, diethyl ether, toluene, dichloromethane, and chlorobenzene, was studied for effective extraction of the colored species from aqueous phase. Chloroform was found to be the most suitable solvent for extraction of colored ion-pair complexes for all reagents quantitatively. Experimental results indicated that double extraction with total volume $5.0 \mathrm{ml}$ chloroform, yielding maximum absorbance intensity, stable absorbance for the studied drugs and considerably lower extraction ability for the reagent blank and the shortest time to reach the equilibrium between both phases.

\section{Effects of reagents concentration}

The effect of the reagents was studied by measuring the absorbance of solutions containing a fixed concentration of MXF, or ENF and varied amounts of the respective reagents. Maximum color intensity of the complex was achieved with $2.0 \mathrm{ml}$ of $1.0 \times 10^{-3} \mathrm{M}$ of all reagents solutions, although a larger volume of the reagent had no pronounced effect on the absorbance of the formed ion-pair complex (Figure 3).

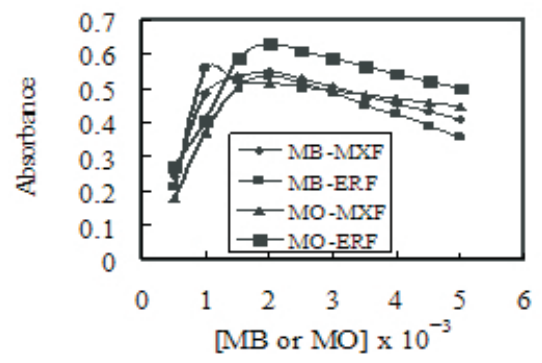

Figure 3: Effect of reagent concentration on the complexation of MXF and ENF

\section{Effect of time and temperature}

The optimum reaction time was investigated from 0.5 to $5.0 \mathrm{~min}$ by following the color development at ambient temperature $\left(25 \pm 2^{\circ} \mathrm{C}\right)$. Complete color intensity was attained after $2.0 \mathrm{~min}$ of mixing for all complexes. The effect of temperature on colored complexes was investigated by measuring the absorbance values at different temperatures. It was found that the colored complexes were stable up to $35^{\circ} \mathrm{C}$. At higher temperatures, the drug concentration was found to increase due to the volatile nature of the chloroform. The absorbance remains stable for $\geq 12 \mathrm{~h}$ at room temperature for all reagents.

\section{Stoichiometric relationship}

The stoichiometric ratio between drug and dye in the ion-pair complexes was determined by the continuous variations method (Figure 4). Job's method of continuous variation of equimolar solutions was employed: a $5.0 \times 10^{-4} \mathrm{M}$ standard solution of drug base and $5.0 \times 10^{-4} \mathrm{M}$ solution of $\mathrm{MB}$, or $\mathrm{MO}$, respectively, were used. A series of solutions was prepared in which the total volume of drug and reagent was kept at $2.0 \mathrm{ml}$ for $\mathrm{MB}$, and $\mathrm{MO}$, respectively. The absorbance was measured at the optimum wavelength. The results indicate that $1: 1$ (drug : dye) ion-pairs are formed through the electrostatic attraction between positive protonated MXF + or ENF+ and negative $\mathrm{MB}-$, and $\mathrm{MO}-$. The extraction equilibrium can be represented as follows:

MXF+ (aq) + D $-($ aq) $\leftrightarrow M X F+D-(a q) \leftrightarrow M X F+D-(o r g), ~(1)$

where MXF + and D - represent the protonated MXF and the anion of the dye, respectively, and the subscripts (aq) and (org) refer to the aqueous and organic phases, respectively.

\section{Conditional stability constants}

The stability of the ion-pair complexes was evaluated. The formation of the ion-pair complexes was rapid and the yellow color extracts were stable at least for $12 \mathrm{~h}$ for drug-dye without any change in color intensity and with the maximum absorbance at room temperature. The conditional stability constants (Kf) of the ion-pair complexes for the studied drug were calculated from the continuous variation data using the following equation [40]:

$$
K_{f}=\frac{A / A_{m}}{\left[1-A / A_{m}\right]^{n+1} C_{M}(n)^{n}}
$$

where $A$ is the observed maximum absorbance, $A m$ is the absorbance value corresponding to intersection of the two tangents of the curve, CM is the mole concentration corresponding to maximum absorbance, and $\mathrm{n}$ is the stoichiometry with which dye ion associates with drugs. The log $\mathrm{Kf}$ values for drug-dye ion-pair associates were calculated in Table 1.

\section{Method of validation}

\section{Linearity}

At described experimental conditions for MXF, and ENF determination, standard calibration curves with reagents were constructed by plotting absorbance versus concentration. The statistical parameters were given in the regression equation calculated from the calibration graphs (Table 1). The linearity of calibration graphs was proved by the high values of the correlation coefficient $(r)$ and the small values of the Y-intercepts of the regression equations. The apparent molar absorptivity of the resulting colored ion-pair complexes and relative standard deviation of response factors for each proposed spectrophotometric method were also calculated and recorded in Table 1. The molar absorptivity of $\mathrm{MO}>\mathrm{MB}$ ion-pair complexes for MXF, while for ENF the molar absorptivity of $\mathrm{MB}>\mathrm{MO}$ ion-pair complexes. 


\section{Sensitivity}

The limits of detection (LOD) and quantitation (LOQ) for the proposed methods were calculated using the following equation $[40,41]$ :

$$
L O D=3 S / k, L O Q=10 S / k
$$

where $S$ is the standard deviation of the response of the blank or the standard deviation of intercepts of regression lines and $k$ is the sensitivity, namely, the slope of the calibration graph. In accordance with the formula, the limits of detection for MXF were found to be 0.53 , and $0.97 \mu \mathrm{g} \mathrm{ml}^{-1}$ for $\mathrm{MB}$, and $\mathrm{MO}$

Table 1: Statistical Analysis for determination of the studied drugs using MB and $\mathrm{MO}$

\begin{tabular}{|c|c|c|c|c|}
\hline \multirow[b]{2}{*}{ Parameters } & \multicolumn{2}{|c|}{ MB } & \multicolumn{2}{|c|}{ MO } \\
\hline & MXF & ENF & MXF & ENF \\
\hline$\lambda_{\text {max }}(n m)$ & 416 & 422 & 415 & 420 \\
\hline $\mathrm{pH}$ & 3.5 & 3.0 & 3.0 & 3.0 \\
\hline Beer's law limits, $\mu \mathrm{g} / \mathrm{ml}$ & $2.0-20$ & $4.0-24$ & $3.0-30$ & $3.0-18$ \\
\hline$\varepsilon,(\mathrm{L} / \mathrm{mol} \mathrm{cm}) \times 10^{4}$ & 1.16 & 1.02 & 1. 32 & 1.98 \\
\hline Sandell sensitivity, $\mathrm{ng} / \mathrm{cm}^{2}$ & 35.97 & 33.71 & 31.22 & 40.13 \\
\hline Regression equation $(y)^{a}$ & & & & \\
\hline Slope (b) & 0.289 & 0.303 & 0.297 & .342 \\
\hline Intercept (a) & -0.0045 & -0.0048 & 0.003 & 0.0062 \\
\hline Correlation coefficient $(r)$ & 0.9992 & 0.9996 & 0.9988 & 0.9994 \\
\hline RSD\% & 0.84 & 1.16 & 1.07 & 1.23 \\
\hline $\mathrm{RE} \%$ & 0.88 & 1.22 & 1.11 & 1.29 \\
\hline SD of blank & 0.0029 & 0.0078 & 0.0056 & 0.0038 \\
\hline LOD $(\mu \mathrm{g} / \mathrm{ml})$ & 0.53 & 0.61 & 0.97 & 0.98 \\
\hline LOO $(\mu \mathrm{g} / \mathrm{ml})$ & 1.93 & 1.97 & 2.95 & 2.99 \\
\hline $\log K_{f}$ & 4.08 & 3.75 & 3.88 & 3.99 \\
\hline t-value ${ }^{b}$ & 1.37 & 1.19 & 1.05 & 1.32 \\
\hline$F$-value ${ }^{b}$ & 2.87 & 2.65 & 2.37 & 2.77 \\
\hline
\end{tabular}

a $y=a+b C$, where $C$ is the concentration in $\mu \mathrm{g} / \mathrm{ml}$,

$y$ is the absorbance.

${ }^{6}$ The theoretical values of $t$ and $F$ at $\mathrm{P}=0.05$ are 2.31 and 6.39 , respectively.

LOD: limit of detection; LOQ: limit of quantification; $\varepsilon$ :molar absorptivity. methods, respectively, Whereas, for ENF the detection limits were found to be $0.61,0.95 \mu \mathrm{g} \mathrm{ml}-1 \mathrm{MB}$, and $\mathrm{M} 0$ methods, respectively. According to this equation, the limit of quantization for MXF was found to be 1.93 , and $2.95 \mu \mathrm{g} \mathrm{ml}^{-1}$ for $\mathrm{MB}$, and $\mathrm{MO}$ methods, respectively. Whereas, for ENF the detection limits were found to be 1.97 , and $2.99 \mathrm{\mu g} \mathrm{ml}^{-1}$ for $\mathrm{MB}$, and $\mathrm{MO}$ methods, respectively.

\section{Accuracy and precision}

Specificity of ion-pair reaction and selective determination of MXF, and ENF which were the basic nitrogenous compounds with acid dyes could be possible. Percentage relative standard deviation (RSD\%) as precision and percentage relative error (RE\%) as accuracy of the suggested methods were calculated. Precision was carried out by six determinations at four different concentrations in these spectrophotometric methods. The percentage relative error was calculated using the following equation:

$$
\mathrm{RE} \%=\frac{\text { found }- \text { added }}{\text { added }} \times 100
$$

The inter-day and intra-day precision and accuracy results are shown in Table 2. These results of accuracy and precision show that the proposed methods have good repeatability and reproducibility.

\section{Robustness and ruggedness}

For the evaluation of the method robustness, some parameters were interchanged: $\mathrm{pH}$, dye concentration, wavelength range, and shaking time. The capacity remains unaffected by small deliberate variations. Method ruggedness was expressed as RSD\% of the same procedure applied by two analysts and with two different instruments on different days. The results showed no statistical differences between procedures done with different analysts and instruments suggesting that the developed methods were robust and rugged.

\section{Effects of interference}

To assess the usefulness of the method, the effect of diluents, excipients, and additives which often accompany MXF and ENF in their dosage forms (starch, lactose, glucose, sucrose, talc, sodium chloride, titanium dioxide, and magnesium stearate) was studied. The results indicated that there is no interference from excipients and additives, indicating a high selectivity for determining the studied MXF, and ENF in their dosage forms.

\begin{tabular}{|c|c|c|c|c|c|}
\hline Method & $\begin{array}{l}\text { Taken } \\
\mu \mathrm{g} / \mathrm{ml}\end{array}$ & $\begin{array}{c}\text { Recovery } \\
\%\end{array}$ & $\begin{array}{l}\text { Precision } \\
\text { RSD \% }\end{array}$ & $\begin{array}{c}\text { Accuracy } \\
\text { RE } \%\end{array}$ & $\begin{array}{c}\text { Confidence } \\
\text { Limit }^{b}\end{array}$ \\
\hline & \multicolumn{5}{|c|}{ Intra-day } \\
\hline MB-MXF & $\begin{array}{l}2.0 \\
4.0 \\
6.0 \\
12 \\
16\end{array}$ & $\begin{array}{l}99.50 \\
99.10 \\
99.40 \\
99.50 \\
101.00\end{array}$ & $\begin{array}{l}0.42 \\
0.69 \\
0.87 \\
0.67 \\
0.81\end{array}$ & $\begin{array}{l}-0.50 \\
-0.90 \\
-0.60 \\
0.35 \\
-0.50\end{array}$ & $\begin{array}{l}1.99 \pm 0.009 \\
3.964 \pm 0.029 \\
5.964 \pm 0.054 \\
11.94 \pm 0.047 \\
16.16 \pm 0.063\end{array}$ \\
\hline MO-ENF & $\begin{array}{l}2.0 \\
4.0 \\
8.0 \\
14 \\
20\end{array}$ & $\begin{array}{l}99.30 \\
99.90 \\
99.20 \\
100.50 \\
99.00\end{array}$ & $\begin{array}{l}0.57 \\
0.80 \\
1.10 \\
0.83 \\
0.97\end{array}$ & $\begin{array}{l}-0.70 \\
-0.10 \\
-0.80 \\
-0.40 \\
-0.075\end{array}$ & $\begin{array}{l}1.986 \pm 0.012 \\
3.996 \pm 0.034 \\
7.936 \pm 0.092 \\
14.07 \pm 0.78 \\
19.80\end{array}$ \\
\hline
\end{tabular}

Table 2. Results of intra-day and inter-day accuracy and precision study for MXF and ENF obtained by the proposed methods. 


\begin{tabular}{|c|c|c|c|c|c|}
\hline Method & $\begin{array}{l}\text { Taken } \\
\mu \mathrm{g} / \mathrm{ml}\end{array}$ & $\begin{array}{c}\text { Recovery } \\
\%\end{array}$ & $\begin{array}{l}\text { Precision } \\
\text { RSD \% }\end{array}$ & $\begin{array}{c}\text { Accuracy } \\
\text { RE \% }\end{array}$ & $\begin{array}{l}\text { Confidence } \\
\text { Limit }^{\mathrm{b}}\end{array}$ \\
\hline & \multicolumn{5}{|c|}{ Intra-day } \\
\hline \multirow[t]{5}{*}{ MB-MXF } & 2.0 & 100.40 & 0.60 & 0.40 & $2.008 \pm 0.013$ \\
\hline & 6.0 & 99.70 & 0.93 & -0.30 & $5.982 \pm 0.058$ \\
\hline & 10 & 99.10 & 1.31 & -0.90 & $9.910 \pm 0.136$ \\
\hline & 15 & 101.00 & 0.97 & -0.80 & $15.15 \pm 0.104$ \\
\hline & 20 & 99.60 & 1.40 & -0.40 & $19.92 \pm 0.146$ \\
\hline \multirow{5}{*}{ MO-ENF } & 2.0 & 99.00 & 0.67 & -1.00 & $1.980 \pm 0.014$ \\
\hline & 6.0 & 100.20 & 0.92 & 0.20 & $6.012 \pm 0.058$ \\
\hline & 10 & 100.50 & 1.25 & 0.50 & $10.05 \pm 0.132$ \\
\hline & 13 & 99.00 & 0.76 & 0.75 & $12.87 \pm 0.112$ \\
\hline & 18 & 99.50 & 1.34 & 0.80 & $17.91 \pm 0.94$ \\
\hline
\end{tabular}

a $\mathrm{RSD} \%$, percentage relative standard deviation; $\mathrm{RE} \%$, percentage relative error.

b Mean \pm standard error.

\section{Analysis of dosage forms}

The proposed methods have been successfully applied to the determination of MXF, and ENF in pharmaceutical dosage forms. Six replicate determinations were made. Moreover, to check the validity of the proposed methods, dosage forms were tested for possible interference with standard addition method (Table 3).

Table 3: Application of the proposed methods for the determination of MXF, and ENF in their pharmaceutical preparations.

\begin{tabular}{|c|c|c|c|c|c|}
\hline \multirow{2}{*}{ Samples } & \multicolumn{2}{|l|}{ MB } & \multicolumn{2}{|l|}{ MO } & \multirow{2}{*}{$\begin{array}{l}\text { Reported } \\
\text { methods }^{c}\end{array}$} \\
\hline & MXF & ENF & MXF & ENF & \\
\hline Avelox tablets & $100.15 \pm 0.74$ & $99.80 \pm 0.71$ & $99.75 \pm 0.53$ & $100.08 \pm 0.56$ & $100.20 \pm 1.59$ \\
\hline $\begin{array}{l}X \pm S D^{a} \\
t-\text { value }^{b} \\
\text { F-value }^{b}\end{array}$ & $\begin{array}{l}1.75 \\
1.15 \\
2.53\end{array}$ & $\begin{array}{l}1.23 \\
1.42 \\
2.87\end{array}$ & $\begin{array}{l}1.11 \\
1.67 \\
3.28\end{array}$ & $\begin{array}{l}1.12 \\
1.53 \\
3.02\end{array}$ & 1.61 \\
\hline Moxiflox tablets & $99.79 \pm 0.57$ & $99.68 \pm 0.80$ & $100.20 \pm 0.77$ & $99.94 \pm 0.68$ & $98.40 \pm 1.73$ \\
\hline $\begin{array}{l}X \pm S d^{a} \\
\text { t-value }^{b} \\
\text { F-value }^{b}\end{array}$ & $\begin{array}{l}1.52 \\
1.27 \\
2.34\end{array}$ & $\begin{array}{l}1.63 \\
1.83 \\
3.11\end{array}$ & $\begin{array}{l}1.73 \\
1.60 \\
2.86\end{array}$ & $\begin{array}{l}1.42 \\
1.43 \\
2.73\end{array}$ & 1.86 \\
\hline Moxifloxacin tablets & $99.03 \pm 0.97$ & $99.60 \pm 0.74$ & $99.35 \pm 0.96$ & $99.50 \pm 0.82$ & $101.80 \pm 1.55$ \\
\hline $\begin{array}{l}X \pm S d^{a} \\
\text { t-value }{ }^{b} \\
\text { F-value }^{b}\end{array}$ & $\begin{array}{l}1.37 \\
1.55 \\
2.74\end{array}$ & $\begin{array}{l}1.21 \\
1.96 \\
3.24\end{array}$ & $\begin{array}{l}1.48 \\
1.32 \\
2.46\end{array}$ & $\begin{array}{l}1.72 \\
1.13 \\
2.38\end{array}$ & 2.42 \\
\hline Avitryl $20 \%$ injectable & $99.85 \pm 0.49$ & $100.05 \pm 0.57$ & $99.60 \pm 0.38$ & $99.70 \pm 0.60$ & $97.75 \pm 1.63$ \\
\hline $\begin{array}{l}X \pm S d^{a} \\
\text { t-value } \\
\text { F-value }^{b}\end{array}$ & $\begin{array}{l}1.52 \\
1.27 \\
2.34\end{array}$ & $\begin{array}{l}1.63 \\
1.83 \\
3.11\end{array}$ & $\begin{array}{l}1.73 \\
1.60 \\
2.86\end{array}$ & $\begin{array}{l}1.42 \\
1.43 \\
2.73\end{array}$ & 1.86 \\
\hline Enrocxin $10 \%$ injectable & $99.62 \pm 0.43$ & $99.15 \pm 0.52$ & $99.50 \pm 0.46$ & $99.34 \pm 0.34$ & $98.25 \pm 1.60$ \\
\hline $\begin{array}{l}X \pm S d^{a} \\
\text { t-value }{ }^{b} \\
\text { F-value }^{b}\end{array}$ & $\begin{array}{l}1.76 \\
1.59 \\
2.92\end{array}$ & $\begin{array}{l}1.39 \\
1.92 \\
3.23\end{array}$ & $\begin{array}{l}1.41 \\
1.32 \\
2.66\end{array}$ & $\begin{array}{l}1.62 \\
1.82 \\
3.073\end{array}$ & \\
\hline
\end{tabular}

${ }^{\text {a }}$ Average of six determinations.

${ }^{\mathrm{b}}$ Theoretical values for $\mathrm{t}$ - and $\mathrm{F}$-values at five degrees of freedom and $95 \%$ confidence limit are $\mathrm{t}=2.57$ and $\mathrm{F}=5.05$

${ }^{\mathrm{c}}$ Reported spectrophotometric methods for , MXF [29], and ENF [33]. 
There was no significant difference between slopes of calibration curves and standard addition methods. Therefore it is concluded that the excipients in pharmaceutical dosage forms of MXF, and ENF were not found any interference in the analysis of MXF, and ENF. At 95\% confidence level the calculated $\mathrm{t}$ - and $\mathrm{F}$ - values did not exceed the theoretical value indicating no significant difference between the proposed methods and the reported methods for MXF [29], and ENF [33] (Table 8).

The results show that satisfactory recovery data were obtained and the assay results were in good agreement with the reported methods.

\section{Conclusion}

This work describes the application of extractive ion-pair complexation reaction with acid dyes for the quantification of some fluoroquinolones antibiotics (MXF, and ENF) in pure forms and pharmaceutical formulations. Compared with the existing visible spectrophotometric methods, the proposed methods have the advantages of being relatively simple, rapid, cost-effective, free from auxiliary reagents, and more sensitive for determination of the studied drugs in pure form and pharmaceutical formulations. Moreover, the proposed methods are free from tedious experimental steps such as heating unlike the previously reported spectrophotometric methods cited earlier. The most attractive feature of these methods is their relative freedom from interference by the usual diluents and excipients in amounts far in excess of their normal occurrence in pharmaceutical formulations. The statistical parameters and the recovery data reveal high precision and accuracy of the methods besides being robust and rugged. Therefore, the validated method could be useful for routine quality control assay of the studied drugs in pure forms and pharmaceutical formulations.

\section{Conflict of interest}

The authors declare that they have no competing interest.

\section{References}

[1] Budavari S, Ed., The Merck Index, Merck and Co., Whitehouse Station, NJ, USA, 13th Edn, 2001.

[2] Sean CS, Martindale, The Complete Drug Reference, Royal Pharmaceutical Society, Pharmaceutical Press, London, UK, 36th Edn, 2009.

[3] Bolon MK, The newer fluoroquinolones, Infectious Disease Clinics of North America, 2009;23: 1027-51.

[4] The United States Pharmacopoeia, 35, NF 30, vol. 1, United States Pharmacopeial Convention, Rockville, Md, USA, 2012.

[5] Shamim S, Sultana N, Arayne MS, Akhtar M, Gul S. Optimization and simultaneous determination of gemifloxacin and non-steroidal antiinflammatory drugs in bulk, pharmaceutical formulations and human serum by RP-HPLC and its applications. Int Res J Pharm \& Pharm 2012; 2:245-53.

[6] Al-Hadiya BMH, Khady AA, Mostafa GAE. Validated liquid chromatographic-fluorescence method for the quantitation of gemifloxacin in human plasma. Talanta 2010; 83(1):110-16.

[7] Amin AS, Dessouki HA, Agwa IA. lon-pairing and reversed phase liquid chromatography for the determination of three different quinolones: enrofloxacin, lomefloxacin and ofloxacin. Arab J Chem 2011; 4:249-57.

[8] Rote AR, Pingle SP. Reverse phase-HPLC and HPTLC methods for determination of gemifloxacin mesylate in human plasma. J Chrom B 2009; 877:3719-23

[9] Sultana N, Arayne MS, Akhtar M, Shamim S, Gul S, Khan MM. Highperformance liquid chromatography assay for moxifloxacin in bulk pharmaceutical formulations and serum: application to in-vitro metal interactions. J Chin Chem Soc 2010; 57:708-17.

[10] Cho SI, Shim J, Kim M-S, Kim Y-K, Chung DS. Online sample cleanup and chiral separation of gemifloxacin in a urinary solution using chiral crown ether as a chiral selector in microchip electrophoresis. J Chrom A 2004; 1055:24145.

[11] Kim E, Koo Y-M, Chung D S. Chiral counter-current chromatography of gemifloxacin guided by capillary electrophoresis using (+)-(18-crown-6)tetracarboxylic acid as a chiral selector. J Chrom A 2004; 1045:119-24.

[12] Faria AF, de Souza MVN, de Almeida MV, de Oliveira MAL. Simultaneous separation of five fluoroquinolone antibiotics by capillary zone electrophoresis. Anal Chim Acta 2006; 579: 185-92.
[13] Radi A, Khafagy A, El-shobaky A, El-mezayen H. Anodic Voltammetric determination of gemifloxacin using screenprinted carbon electrode. J Pharm Anal 2013; 3: 132-36,

[14] Ensaifi AA, Khayamian T, Taei M. Determination of ultra trace amount of enrofloxacin by adsorptive cathodic stripping voltammetry using copper(II) as an intermediate. Talanta 2009; 78:942-48.

[15] Radi A-E, Wahdan T, Anwar Z, Mostafa H. Electrochemical determination of gatifloxacin, moxifloxacin and sparfloxacin fluoroquinolonic antibiotics on glassy carbon electrode in pharmaceutical formulations. Drug Testing \& Anal 2010; 2:397-400

[16] Al-Ghannam S M. Atomic absorption spectroscopic, conductometric and colorimetric methods for determination of some fluoroquinolone antibacterials using ammonium reineckate, Spectrochim Acta A 2008; 69:1188-94.

[17] Salem H. Spectrofluorimetric, atomic absorption spectrometric and spectrophotometric determination of some fluoroquinolones. Am J Appl Sci 2005; 2:719-29.

[18] Tekkeli SEK, Onal A. Spectrofluorimetric methods for the determination of gemifloxacin in tablets and spiked plasma samples. J Fluor 2011; 21:1001-07.

[19] Kamruzzaman M, Alam A-M, Lee SH, et al. Method for determination of fluoroquinolones based on the plasmonic interaction between their fluorescent terbium complexes and silver nanoparticles. Microchim Acta 2011; 174:35360.

[20] Ulu ST. Rapid and sensitive spectrofluorimetric determination of enrofloxacin, levofloxacin and ofloxacin with 2,3,5,6-tetrachloro-pbenzoquinone. Spectrochim Acta A 2009; 72:1038-42.

[21] Salama FM, Attia KA, Abouserie AA, El-Olemy A, Abolmagd E. Potentiometric determination of enrofloxacin using PVC and coated graphite sensors. Open Access J Chem 2018; 2:38-46.

[22] Dhumal DM, Shirkhedkar AA, Surana SJ. Quantitative determination of moxifloxacin hydrochloride in bulk and ophthalmic solution by UVspectrophotometry and first order derivative using area under curve. Der Pharm Lett 2011; 3:453-56.

[23] Misra MK, Misra A, Zope P, Panpalia GM, Dorle AK. Simple and validated UV-spectroscopic method for estimation of moxifloxacin. $\mathrm{HCl}$ in bulk and formulation. J Global Pharm Tech 2010; 2:21-27.

[24] Patel PU, Suhagia BN, Patel MM. Spectrophotometric methods for estimation of moxifloxacin in pharmaceutical formulations. Indian Drugs 2005; 42:654-57.

[25] Ciric A, Jelic R, Joksovic L, Jelikic-Stankov M, Djurdjevic P. Determination of moxifloxacin in human plasma by derivative UV spectrophotometry in a micellar medium. Canad J Anal Sci \& Spect 2007; 52:343-50.

[26] Motwani SK, Chopra S, Ahmad FJ, Khar RK, Validated spectrophotometric methods for the estimation of moxifloxacin in bulk and pharmaceutical formulations. Spectrochim Acta A 2007; 68:250-56.

[27] Sultan MA. New, simple and validated kinetics spectrophotometric method for determination of moxifloxacine in its pharmaceutical formulations. Arab J Chem 2009; 2:79-85.

[28] Chaple DR, Bhusari KP. Spectrophotometric estimation of fluroquinolones as ion-pairs with bromocresol green in bulk and pharmaceutical dosage form. Asian J Chem 2010; 22: 2593-98.

[29] Abdellaziz LM, Hosny MM. Development and validation of spectrophotometric, atomic absorption and kinetic methods for determination of moxifloxacin hydrochloride. Anal Chem Insights 2011; 6:67-78.

[30] Ragab GH, Amin AS. Atomic absorption spectroscopic, conductometric and colorimetric methods for determination of fluoroquinolone antibiotics using ammonium reineckate ion pair complex formation. Spectrochim Acta A, 2004; 60:973-78.

[31] Sastry CSP, Rao KR, Prasad DS. Extractive spectrophotometric determination of some fluoroquinolone derivatives in pure and dosage forms. Talanta 1995; 42:311-16.

[32] Mostafa S, El-Sadek M, Alla EA. Spectrophotometric determination of ciprofloxacin, enrofloxacin and pefloxacin through charge transfer complex formation. JPharm \& Biomed Anal 2002; 27:133-42.

[33] Mostafa S, El-Sadek M, Alla EA. Spectrophotometric determination of enrofloxacin and pefloxacin through ion-pair complex formation. J Pharm \& Biomed Anal 2002; 28:173-80.

[34] Rizk M, Belal F, Ibrahim F, Ahmed SM, El-Enany NM. A simple kinetic spectrophotometric method for the determination of certain 4-quinolones in drug formulations. Sci Pharm 2000; 68:173-88. 
[35] El Sherif ZA. Spectrophotometric determination of enrofloxacin through the formation of a binary complex with iron III, ion-pair and charge-transfer complexation in pure and dosage forms. Anal Lett 1999; 32:65-78.

[36] Sastry CSP, Rao KR, Lingeswara JSVM, Prasad DS. Two simple spectrophotometric methods for the assay of enrofloxacin in pharmaceutical dosage formulations. Eastern Pharm 1995; 38:143-44.

[37] Britton HTS. Hydrogen lons, Chapman \& Hall, New York, NY, USA, 4th edition, 1952.

[38] Job P. Spectrochemical Methods of Analysis, Wiley Interscience, New York, NY, USA, 1971
[39] Yoe JH, Jones AL. Determination of tungsten. Ind \& Eng Chem Anal Ed 1944;16: 111.

[40] International Conference on Harmonization of Technical Requirements for Registration of Pharmaceuticals for Human Use, ICH Harmonized Tripartite Guideline, Validation of Analytical Procedures: Text and Methodology, 02(R1), Complementary Guideline on Methodology dated 06 November 1996, ICH, London, UK, 2005.

[41] Miller JN, Miller JC. Statistics and Chemometrics for Analytical Chemistry, Chapman \& Hall/CRC, London, UK, 5th Edn, 2005. 